Revista Estudios, (36), 2018.

Junio 2018-Noviembre 2018

ISSN 1659-3316

Mendoza Álvarez José David

III Sección Arte, arquitectura y cine

\title{
Cuerpo intermedio de separación entre gradas en el Anfiteatro de Itálica (Santiponce, España)
}

\author{
José David Mendoza Álvarez \\ Escuela Técnica Superior de Arquitectura \\ Universidad de Sevilla, España \\ luckyman76@hotmail.com \\ https://orcid.org/0000-0001-8909-6077
}

Recibido: 10 de diciembre de 2017

Aceptado: 24 de abril de 2018

\section{Resumen}

Pretendemos mostrar la restitución del anfiteatro de Itálica (Santiponce, España), que presenta los niveles superiores desaparecidos. Gracias a la reinterpretación de las imágenes, textos, archivos, documentos y fotografías de distintas épocas, hemos conseguido restituir su forma correcta en cuanto al número de gradas de cada cuerpo, fachadas, escalera perimetral, arquitectura, historiografía, geometría y aforo, objetivos de esta investigación.

Palabras Clave: Arqueología; Arquitectura; Historia; Historiografía; Antigüedad

Intermediate structure of separation between grades in The Italica Amphitheater (Santiponce, Spain)

\footnotetext{
Abstract

We intend to show the restitution of the Itálica amphitheater (Santiponce, Spain), which presents the disappeared superior levels. Thanks to the reinterpretation of images, texts, archives, documents and photographs from different periods, we have managed to restore its correct form in terms of the number of steps of each

\section{cc) () (2)}

La Revista Estudios es editada por la Universidad de Costa Rica y se distribuye bajo una Licencia Creative Commons Atribución-NoComercial-Compartirlgual 3.0 Costa Rica. Para más información envíe un mensaje a revistaestudios.eeg@ucr.ac.cr.
} 
Revista Estudios, (36), 2018.

ISSN 1659-3316

Junio 2018-Noviembre 2018

Mendoza Álvarez José David

level, facades, perimeter staircase, architecture, historiography, geometry and capacity, objectives of this investigation.

Keywords: Archeology; Architecture; History; Historiography; Antiquity

\section{1.- INTRODUCCIÓN}

Italica fue fundada por Escipión en el contexto de la II Guerra Púnica, tras la batalla de llipa (Apiano, Iber., 38), manteniendo una guarnición permanente y denominándola Itálica por la procedencia de los soldados que acantonó en el lugar (Blázquez, 1991, pp. 285-286; Rodríguez Hidalgo y Keay, 1995, p. 397). Se creó sobre un oppidum turdetano ${ }^{1}$ existente desde el siglo V-IV a.C., siendo elevada a la condición de municipio bajo Augusto $^{2}$ por haber servido al bando cesariano como se cree generalmente, y con Adriano se elevó a colonia (Morales Cara, 2005, p. 455; Amela, 2011, p. 31), recogido por Aulo Gelio (Noctes Atticae, XVI, 13.4) y reflejado en la epigrafía (CIL II, 1135; CIL XI, 2699; CIL XII, 1856) entre otros ejemplos (Blázquez, 1982, p. 308). Se ubica en altura, en un lugar estratégico desde donde se domina la Vega del Guadalquivir (García y Bellido, 1960, p. 21).

Respecto al objeto de estudio de esta investigación, el anfiteatro de Italica se sitúa al norte de la actual ciudad de Santiponce, en la ampliación adrianea, con una dirección este-oeste (De los Ríos, 1916a, p. 381; Chisvert, 1987, p. 282; Muñoz Garrido, 2002, p. 246). Debemos destacar las condiciones topográficas del sitio donde se ubica el anfiteatro (De los Ríos, 1916a, p. 406), hecho fundamental a la hora de entender cómo se ha conservado el edificio en sus niveles inferiores a pesar del gran expolio sufrido durante siglos pues el edificio se construye aprovechando dos cerros donde previamente se canalizó el arroyo que entre los mismo discurría (Golvín, 1988, p. 200; Roldán, 1994, p. 215; Larrey, Ramón y

\footnotetext{
${ }^{1}$ En contra de lo que se estimaba, Italica no se erigió junto a un núcleo turdetano, sino sobre el propio asentamiento turdetano (Abascal y Espinosa, 1989, p. 27; Corzo, 2002, p. 7).

${ }^{2}$ Con Augusto sería elevada al rango de municipio junto a un programa urbanístico monumental, aunque se debe tener en cuenta si se trataba de un Municipium Iuris Latini o un Municipium Ciuium Romanorum (Rodríguez Hidalgo y Keay, 1995, p. 399).
}

\section{(c) (i) (2) (2)}

La Revista Estudios es editada por la Universidad de Costa Rica y se distribuye bajo una Licencia Creative Commons Atribución-NoComercial-Compartirlgual 3.0 Costa Rica. Para más información envíe un mensaje a revistaestudios.eeg@ucr.ac.cr. 
Verdugo, 1998, p. 1081; Pellicer, 1999, p. 178; Hidalgo, 2008, p. 223), siendo necesaria el acondicionamiento de estos cerros en una forma llamada por Golvín y utilizada por otros investigadores como estructura mixta (Golvín, 1988, p. 157; Roldán, 1993, p. 98; Corzo, 1994, pp. 187-192; Bellido, 2009, p. 35). Respecto a esto, Demetrio de los Ríos interpretó que el edificio se erigiría desde el nivel de la arena, hecho refutado por su sobrino Rodrigo Amador de los Ríos, error que pudo deberse al estado en el que contempló el edificio por primera vez Demetrio en la década de los cuarenta del siglo XIX e incluso llegando a confeccionar una planta que debemos interpretar no como la del primer cuerpo del edificio italicense sino la del segundo (De los Ríos, 1862, p. 24; De los Ríos, 1916a, p. 383; Chisvert, 1987, pp. 282-288).

A lo largo de su historia ha sufrido numerosos avatares, desde la utilización como cantera de sus restos a las excavaciones incontroladas y expolio. Sería el siglo XIX el momento de mayor destrucción del mismo y a la vez el siglo en el que comenzarían las principales excavaciones y medidas de protección. Pero un hecho de suma importancia ha pasado desapercibido en las investigaciones y nos ha permitido establecer nuestras hipótesis y proporcionar una nueva restitución del anfiteatro. Se trata de la gran colmatación que lo protegía paulatinamente de cada acometida para extraer sus restos, constatándose un primer nivel a una altura de 18 metros sobre el nivel de la arena del propio edificio, para el siglo XVI, y de unos 8 metros a mediados del siglo XIX. De esta forma, presentamos los resultados de nuestras investigaciones en torno al edificio, y las hemos marcado en un contexto general donde tratamos todos los anfiteatros romanos distribuidos entre Europa, Asia y norte de África.

\section{2.- PRECEDENTES}

En primer lugar, tenemos que comentar una serie de datos concernientes al origen de los juegos anfiteatrales que dio lugar a la creación de edificios concretos para albergarlos. En segundo lugar mencionaremos las partes básicas que de forma

\section{(c) (i) (2)}

La Revista Estudios es editada por la Universidad de Costa Rica y se distribuye bajo una Licencia Creative Commons Atribución-NoComercial-CompartirIgual 3.0 Costa Rica. Para más información envíe un mensaje a 
tradicional componen un anfiteatro. En tercer lugar, destacaremos un nuevo elemento común en muchos anfiteatros analizados, determinándolo también para el caso italicense del cual hablaremos en cuarto lugar ofreciendo los datos básicos que de él se conocen, tales como origen, localización y contexto, presentando en última instancia los pasos que hemos seguido para llegar a la demostración de nuestras hipótesis que a su vez implican el poder realizar no sólo la nueva composición edilicia, sino el cálculo de su aforo más aproximado.

El precedente de los espectáculos provino del mundo griego, según refiere J. M. Blázquez, comenzando mediante competiciones atléticas y luchas hasta que fue modificado y configurado por el mundo etrusco que lo adaptó a contextos funerarios (Blázquez, 1994, p. 31; 2006, p. 26; Ceballos y Ceballos, 2003, p. 57; Gómez Pantoja, 2006, p. 169; Santos Yanguas, 2008, p. 188), pasando la tradición a Roma posteriormente (Blázquez, 2006, p. 14), que además de otorgarle un carácter funerario en los primeros momentos de su adopción en el siglo III a.C. (Fabié, 1892, p. 392; Ceballos, 2007b, p. 107), fue tornándose en meramente lúdico, político y religioso, hasta el punto de configurarse como una herramienta para controlar a las masas (Blázquez, 2006, p. 18; Pina Polo, 2007, p. 143; Cabrero y Cordente, 2011, p. 363). Pero era necesario la creación de un espacio para ello, ya que los lugares habilitados en primera instancia no eran del todo seguro, o no ofrecían un acondicionamiento que permitiese el disfrute de los eventos, como en el caso de los foros (Livio, XXVIII, 21), condicionado a un espacio rectangular (García Naranjo, 1951, p. 8), hecho que motivó la creación de edificios en primer lugar con forma circular y posteriormente confeccionando formas geométricas ovaladas o elípticas, donde el ángulo de visión sería corregido así como la seguridad de los espectáculos (Wilson, 1993, pp. 391-392).

Se tiene constancia documental que en el Campo de Marte se construyó un gran anfiteatro de la mano de Cayo Statilio Tauro, en época augustea, que fue destruido en el incendio en tiempos de Nerón (Lipsio, 1598, p. 15; VVAA, 1845, p. 169; García Naranjo, 1951, p. 8). Previamente en el 53 a.C. se había construido 
un sistema que permitía girar dos teatros de maderas levantados sobre mecanismos adecuados, para enfrentar sus scaenae donde se realizaban los espectáculos, de la mano de Cayo Curio Escriboniano, originándose de esta forma el significado de la palabra anfiteatro (Cabrero y Cordente, 2011, p. 369). Sobresalieron estos edificios mediante su edilicia en piedra que soportaba muy bien el peso de los espectadores para evitar tragedias como el desplome de las gradas de madera por no poder con el peso de un gran número de espectadores en algunos casos o los incendios en otros. Gracias a un entramado de arcos y bóvedas en piedra y cemento, fue posible la construcción en altura de estos edificios (Santos Yanguas, 2008, p. 188).

Por lo general, serían las vías de comunicaciones los ejes donde se vertebran las construcciones de estos edificios, marcándose en las provincias fundamentalmente, siendo la vía Augusta y la de la Plata para la Península Ibérica los ejes principales (González Blanco, 1988, p. 244; Sillières, 1990; Melchor, 1992, pp. 121-122; Guerra, 2005, p. 563; Ceballos, 2007a, p. 442; Cortijo, 2008, p. 289). En estos nuevos edificios podían darse juegos gladiatorios o munus, venationi y ejecuciones, en verdaderas pantomimas y decoraciones teatrales (Ceballos y Ceballos, 2003, p. 57; Garrido, 2005, p. 162; Blázquez, 2006, p. 24; Cabrero y Cordente, 2011, p. 364). En algunos edificios se dieron naumachias aunque no era habitual pues para ello se realizaron edificios acondicionados a tal efecto (Suetonio, Caes. 39 y 44; Marcial, Epigr. 26 y 28), debiéndose indicar que en Italica nunca se dieron estos espectáculos navales (Cabrero y Cordente, 2011, p. 372).

Los anfiteatros eran espacios considerados como fuente de disturbios, teniendo en Pompeya el ejemplo más radical cuando, debido a unos violentos disturbios en su interior con los vecinos de Nocera que acudieron al evento en el año 59, el Senado determinó su cierre como sanción durante diez años (Cabrero y Cordente, 2011, p. 369). De esta forma distinguimos una división tradicional del interior de los anfiteatros (García Naranjo, 1951, p. 10; Gros, 1994, p. 13; Beltrán 
Llorís, 1997, p. 28; González, 2002, pp. 81-90), encontrándonos desde la arena como primer elemento un podium espacioso al que le continuaba una primera grada o ima cavea, reservada para magistrados, senadores y determinada élite; por lo general cada cavea solía estar divididas por praecintio y pequeño muro de delimitación o balteus; un segundo cuerpo lo componía la media cavea, la cual solía estar reservada a los caballeros unas catorce filas de gradas reguladas por la Ley Roscia; a continuación se solía construir el tercer cuerpo o summae cavea, colmatado por el cuerpo final o porticus in summae cavea el cual, reservado a mujeres y esclavos, dispondría de espacio suficiente para almacenar los útiles del velamen que desde la terraza superior sería extendido por un cuerpo de marineros expertos. A todo ello debemos esclarecer que no siempre la edilicia era la misma pues los condicionantes como el terreno o la monumentalidad del edificio implicaban construir menos cuerpos.

\section{3.- ESTRUCTURA INTERMEDIA ENTRE LAS CÁVEAS}

En nuestra investigación ha sido preciso analizar las imágenes, ilustraciones y grabados así como los datos técnicos oficiales que se han recopilado del anfiteatro prácticamente desde el siglo XVII gracias a las cuales podemos determinar que el edificio mantuvo sus partes más elevadas hasta prácticamente mediados del siglo XIX. A continuación y de forma muy breve, comentaremos los dibujos más importantes y las fuentes documentales que nos han permitido establecer tales cuestiones, aunque no sin antes determinar las partes básicas que componen el anfiteatro de Italica y la nueva arquitectura que pretendemos con este estudio. De forma interna, estos sectores ya conocidos son la arena con su foso bestiario, el podium, la ima, media y summae cavea y la terraza, mientras que en el exterior se piensa que tendría una sucesión de cuerpos de arcadas, tres para las partes principales este y oeste, y dos en los lados norte y sur al apoyar estos sectores en sendos cerros, además de señalarse una escalera perimetral externa. En nuestro estudio determinamos una fachada de perímetro continuo, con planta elíptica, en

\section{(c) (i) (9) (2)}

La Revista Estudios es editada por la Universidad de Costa Rica y se distribuye bajo una Licencia Creative Commons Atribución-NoComercial-CompartirIgual 3.0 Costa Rica. Para más información envíe un mensaje a revistaestudios.eeg@ucr.ac.cr. 
Revista Estudios, (36), 2018.

Junio 2018-Noviembre 2018

ISSN 1659-3316

Mendoza Álvarez José David

la que la escalera perimetral transcurriría por el interior del diseño del anfiteatro, presentando tres cuerpos de arcadas en los lados este y oeste, y dos en las partes norte y sur, más un cuerpo de ático.

De forma interna debemos señalar la existencia de un nuevo elemento objeto de este estudio, un cuerpo que se detecta en otros anfiteatros con la misma cronología adrianea y hemos podido determinar para el italicense gracias al análisis que realizamos, señalando que presenta las mismas dimensiones que el cuerpo del podium con el que fue confundido inicialmente. Este elemento, más allá de ser una composición arquitectónica decorativa, se presenta con una doble funcionalidad, la de distribución de espectadores mediante sus aperturas, escaleras y galerías, y por su composición edilicia, la de soportar los empujes, fuerza y peso del resto de la estructura superior. A esta estructura la hemos denominado cuerpo intermedio ${ }^{3}$ entre las cáveas segunda y tercera, a modo de diferenciación de partes internas del anfiteatro, y suele aparecer entre las gradas a modo de barrera física para evitar los disturbios entre las clases sociales, como en los ejemplos más cercanos de Nimes (Esperandieu, 1933, p. 43), Puteoli (Maiuri, 1955, p. 16) y Cagliari (Pala, 2002, p. 22; Dadea, 2006, p. 6-9), tanto en composición como en cronología adrianea, estando situado en Italica entre la media y summae cavea, por lo que nuestra restitución podemos establecerla de la siguiente forma: arena con foso bestirario, delimitada por un cuerpo de podium al que le sigue la ima cavea con ocho filas de gradas, una primera praecintio con balteus que darían paso a la media cavea con catorce filas de gradas, tras la cual se erigiría el cuerpo intermedio, la summae cavea con veinte filas de gradas y el porticus in summae cavea (Fig. 1). Gracias a esta distribución, finalmente, podemos realizar un nuevo cálculo de su aforo.

\footnotetext{
${ }^{3}$ Véase la tesis recientemente defendida: Mendoza Álvarez, J. D. (2017): Análisis historiográfico del anfiteatro de Itálica. Tesis Doctoral, Morrisville, Carolina del Norte (EEUU), que dedica gran parte de la investigación a la restitución del edificio, constitución del cuerpo intermedio y los niveles superiores hoy día desaparecidos, y otros elementos inéditos del resto de la estructura.
}

La Revista Estudios es editada por la Universidad de Costa Rica y se distribuye bajo una Licencia Creative Commons Atribución-NoComercial-Compartirlgual 3.0 Costa Rica. Para más información envíe un mensaje a revistaestudios.eeg@ucr.ac.cr. 


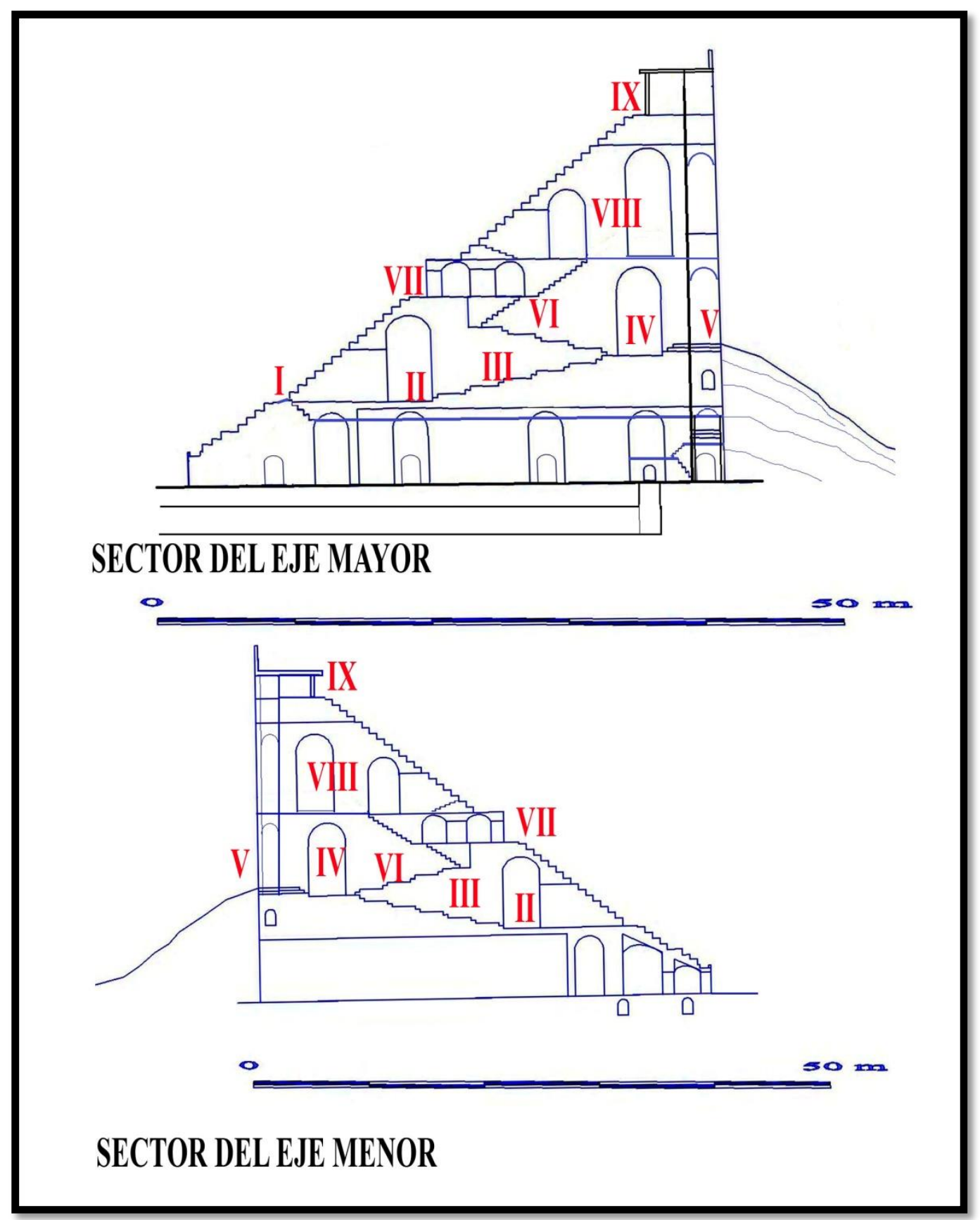

Fig. 1.- Restitución del anfiteatro según el autor. Praecintio de la primera grada (I); galería anular interior del cuerpo medio (II); escaleras de acceso entre galerías (III); galería anular exterior del cuerpo medio (IV); escalera perimetral externa (V); restitución de las escaleras que conducían al cuerpo intermedio (VI); cuerpo intermedio de separación entre cáveas (VI); galerías anulares del tercer cuerpo (VIII); pórtico superior (IX).

\section{(c) (i) (2) (2)}

La Revista Estudios es editada por la Universidad de Costa Rica y se distribuye bajo una Licencia Creative Commons Atribución-NoComercial-Compartirlgual 3.0 Costa Rica. Para más información envíe un mensaje a revistaestudios.eeg@ucr.ac.cr. 
Tras su abandono, el anfiteatro de Itálica sería desmontado progresivamente para la reutilización de sus materiales, lo que condicionó la visión que del mismo fueron mostrando los distintos estudiosos. En 1548, Pedro de Medina describió los restos de Itálica como "pedazos de edificios muy antiguos", y en particular, los restos del anfiteatro como "un coliseo con muchas puertas o ventanas" (De Medina, 1566, p. 52; De los Ríos, 1916a, p. 388; 1916b, p. 8). El grabador Flamenco Antón Van Den Wyngaerde dibujó el anfiteatro en 1567 (Luzón, 1999, p. 25; Rodríguez Hidalgo, 2010, p. 22; 2012a, p. 127; 2012b, p. 16), añadiendo la leyenda: "Coliseo de Sebilia La Vechia alrededor tiene 506 pasos" (Luzón, 1999, p. 27). Esta primera imagen artística no ha sido analizada en la forma que debiera pues tan solo se aprecian restos sin escala, muy colmatados, que parecen estar siendo desmontados (Bellido, 2009, p. 40). No obstante, si prestamos atención a los detalles podemos reconocer un cuerpo intermedio, una serie de cunei con sus vomitoria, colmatación de la arena hasta niveles muy elevados y destrucción de la parte superior y externa del edificio. En el dibujo de G. Braum de 1588 parece apreciarse cómo se intenta recrear los niveles superiores muy derruidos, así como un interior donde creemos apreciar el cuerpo intermedio con numerosas entradas. En la imagen posterior de Diego de Cuelvis (Fig. 2) vemos un edificio representado de forma idílica, aunque no por ello deja de presentarnos detalles, ya que apreciamos tanto en el interior como en el exterior, numerosas aperturas, pudiendo referirse las de su interior a los vomitoria o a las puertas del cuerpo intermedio (Rodríguez Hidalgo, 2012a, p. 128; 2012b, p. 16).

\section{(c) (i) (2)}

La Revista Estudios es editada por la Universidad de Costa Rica y se distribuye bajo una Licencia Creative Commons Atribución-NoComercial-CompartirIgual 3.0 Costa Rica. Para más información envíe un mensaje a 


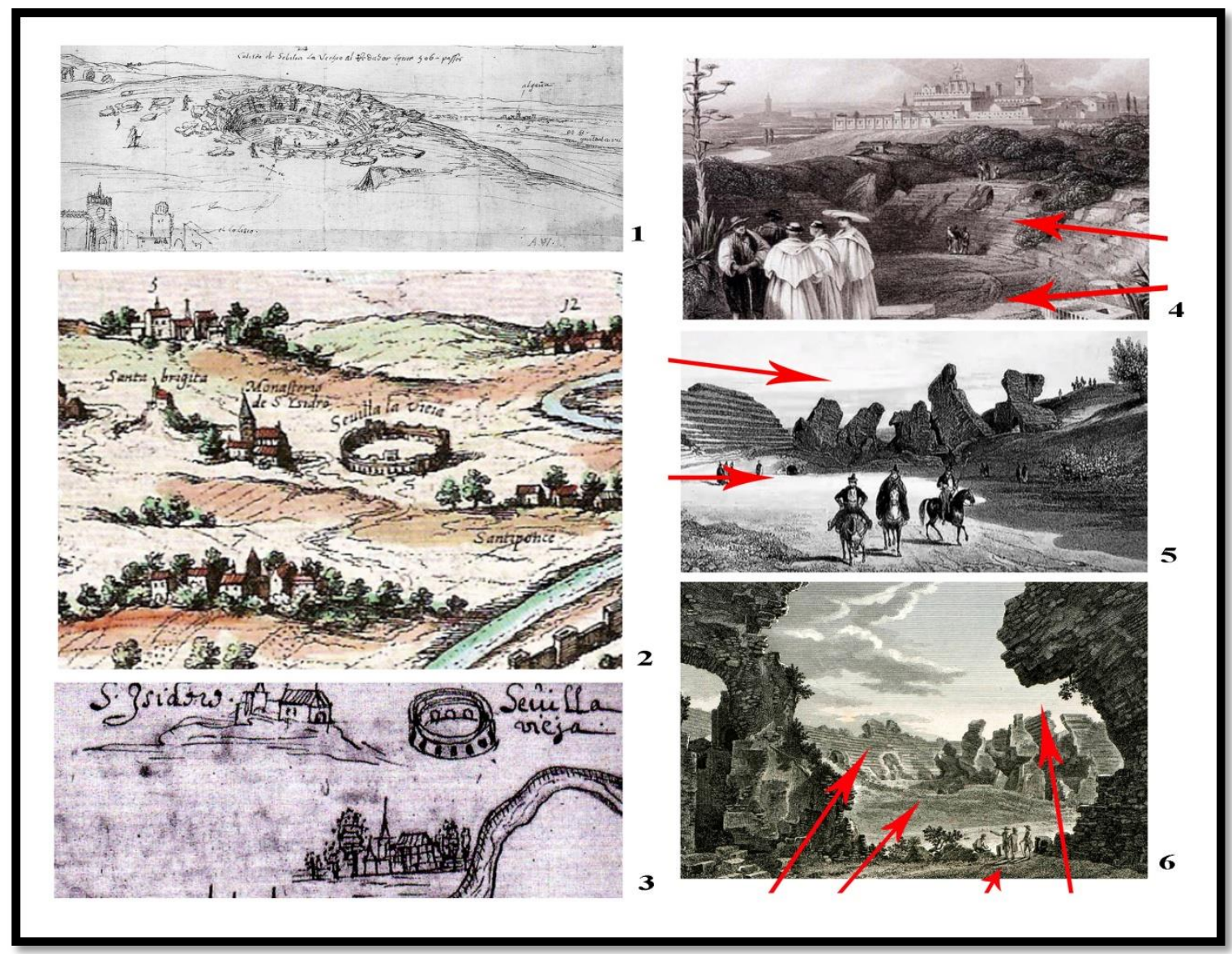

Fig. 2.- Imágenes del anfiteatro de Itálica según los dibujos de Wyngaerde (Beltrán Fortes y Rodríguez Hidalgo, 2004, p. 36; Bellido, 2009, p. 40; Caballos, 2010, p. 22) (1); Braum y Hegenbergius (1588, p. 2) (2); Cuelvis (Caballos, 2010, p. 20) (3); David Robert en 1835 (Canto, 1999, p. 187; Caballos, 2010, p. 73) (4); Taylor (1832) (5); y Alexandre Laborde (Beltrán Fortes y Rodríguez Hidalgo, 2004, p. 36; Salas, 2004, p. 223; 2007, p. 20; 2009, pp. 57-72) (6).

Desde el siglo XVI se cuenta con descripciones del anfiteatro de Italica que deben de ser entendidas según el momento en el que fueron redactadas, ya que el edificio se encontraba muy condicionado por la colmatación existente hasta mediados del siglo XIX, y los continuos destrozos que distorsionarían su imagen, como podemos interpretar en Ambrosio de Morales que en 1575 no sabe determinar si se trataba de un teatro o un anfiteatro el edificio que contemplaba

\section{(c) (i) (2)}

La Revista Estudios es editada por la Universidad de Costa Rica y se distribuye bajo una Licencia Creative Commons Atribución-NoComercial-Compartirlgual 3.0 Costa Rica. Para más información envíe un mensaje a revistaestudios.eeg@ucr.ac.cr. 
(De Morales, 1575, pp. 83-84). A finales del siglo aparece en escena Rodrigo Caro, testigo de primera mano del traslado del caserío de Santiponce al lugar donde hoy lo conocemos. Pero no sería hasta el siglo XVII cuando Caro identificase las ruinas conocidas como "Sevilla la Vieja" con Italica (García y Bellido, 1960, p. 63). Recoge del anfiteatro que era una "obra insigne destruido en la mayor parte, todavía conserva la forma circular, aunque se llega al óvalo con 65 pasos de diámetro" (Caro, 1634, p. 110). Ahí presentamos la primera prueba más fiable de la existencia de una gran colmatación del interior de la arena hasta una altura calculada por nosotros que alcanzaría entre los 15 y 18 metros, no sólo al convertir los pasos de la época en metros actuales, sino al tener en cuenta la descripción de Caro que realiza sobre un posible podium y enumerando veinte filas de gradas sobre el mismo sin praecintio, hecho que no podemos entender que se tratase del verdadero podium pues éste presentaría a continuación la ima cavea con ocho filas de gradas, y sería desenterrado por Demetrio de los Ríos en la década de los años sesenta del siglo XIX.

Respecto a las dimensiones del edificio, tanto Golvín como García Naranjo coinciden en que los ejes máximos del anfiteatro se establecen en 156,5×134 m mientras que los ejes que conformarían la arena comprenderían los 71,5x49 m (García Naranjo, 1951, p. 13; Golvín, 1988, p. 200). A su vez, M. Wilson Jones establece unas diferencias mínimas según su estudio geométrico, pues comprende unos ejes máximos de 153×128,25 m y unos mínimos de 70,7×45,95 (Wilson, 1993, p. 442). Esto ha sido una constante con la que nos hemos encontrado al determinar las medidas de algunos de los anfiteatros analizados donde comprobamos que los autores no logran ponerse de acuerdo para establecer unas medidas reales que en ocasiones varían algunos metros, como en el caso del Coliseo. En nuestro caso, los cálculos de Caro nos indican unos 65 pasos que corresponden a 325 pies lo cuales a su vez, para un pie de 0,29 m nos da una cifra de 94,25 m, que si lo aplicamos a la descripción del edificio del momento, llegamos a la conclusión que estaría colmatado a una altura estimada 
entre 15 y $18 \mathrm{~m}$, correspondiente valga la casualidad al final de la media cavea conocida en la actualidad, lugar desde donde se erigiría el cuerpo intermedio de distribución de peso del resto del edificio, conformando un aspecto similar al podium, con el que sería confundido por estos autores desde R. Caro, de la misma forma que hemos podido ver y comparar en otros anfiteatros como el de Nimes o Cagliari.

Así mismo, hemos podido establecer una primera correspondencia entre el texto de Caro y la imagen de Wyngaerden que de forma artística nos representaría el tercer cuerpo muy colmatado. La segunda correspondencia la extraemos en el siglo XVIII del texto de Enrique Flórez y las plantas del edificio de Manuel Martí y las de Juan de Espinar, además de los grabados artísticos que fueron realizándose desde este momento con más lujo de detalles. En esta ocasión, Flórez contabiliza unas 15 filas de gradas que arrancan desde el podium y deben entenderse como parte de las correspondientes del tercer cuerpo, el mismo que vio Caro, el cual estaría siendo desmontado lenta y paulatinamente, y no se debe intentar demostrar que Flórez se referiría a la media cavea actual, debiendo indicar que hemos contabilizado in situ unas 14 filas de gradas comprobando como en la parte superior de la bóveda aún conservada, se extendería una planicie la cual debía corresponder al suelo del cuerpo intermedio. Este error ha condicionado toda la investigación posterior y nos ha permitido establecer nuestras hipótesis sobre el cuerpo intermedio y la tercera cavea (Flórez, 1776, p. 234; De los Ríos, 1916a, p. 391). Además de ello, Flórez habla de bóvedas y la existencia de 16 puertas distribuidas en 8 a cada lado del eje mayor (Flórez, 1776, p. 235), lo que debemos interpretar que los restos del tercer graderío situado sobre las puertas principales al este y oeste, al estar confeccionado sobre espacios abovedados y ser desmontados, junto a la acción de la dilatación del terreno por estar sobre una vaguada y sobre todo por el gran terremoto de Lisboa de mediados del siglo XVIII, la fuerza de la gravedad haría que las moles de opus caementicium del que estaba compuesto las gradas, cayesen de la forma similar a 
ISSN 1659-3316

Junio 2018-Noviembre 2018

Mendoza Álvarez José David

cómo podemos ver hoy los fragmentos de la segunda cavea, lo que induce nuevamente al error al tomar los grabados del momento y querer ver que se representaban el segundo cuerpo.

Flórez habla de 291 pies castellanos para su eje mayor (Flórez, 1776, p. 236), lo que siguiendo el mismo razonamiento de Caro, y atendiendo a la medida del pie castellano, algo más pequeño que el romano, obtenemos unos $81,5 \mathrm{~m}$. De ello podemos deducir que en tiempos de Flórez, ha disminuido algo la colmatación existente en el interior de la arena. En esta ocasión, acompañamos las referencias textuales con las plantas realizadas ya en el siglo XVIII las cuales digitalizamos y superpusimos con la sorpresa que coincidían con el edificio italicense en modulación conforme se levantaba en altura. Así mismo, presentamos una nueva planta realizada por los topógrafos militares y recogida en el Archivo Histórico Militar $^{4}$ (Salas, 2004, p. 682), la cual hemos determinado que correspondería al cuerpo intermedio. Esto viene a significar que la medida del largo de la cavea que presentarían las plantas consultadas, las de Martí, Flórez y AHM, se reducirían respecto al distinto nivel de altura al cual correspondería, y serían muy diferentes a las que trazó Demetrio de los Ríos ya en el siglo XIX, la cual hemos identificado como perteneciente al segundo cuerpo gracias a los detalles que la obra de Demetrio nos ofrece y hemos podido comprobar (Fig. 3).

\footnotetext{
${ }^{4}$ AHM en adelante.

La Revista Estudios es editada por la Universidad de Costa Rica y se distribuye bajo una Licencia Creative Commons Atribución-NoComercial-CompartirIgual 3.0 Costa Rica. Para más información envíe un mensaje a revistaestudios.eeg@ucr.ac.cr.
} 


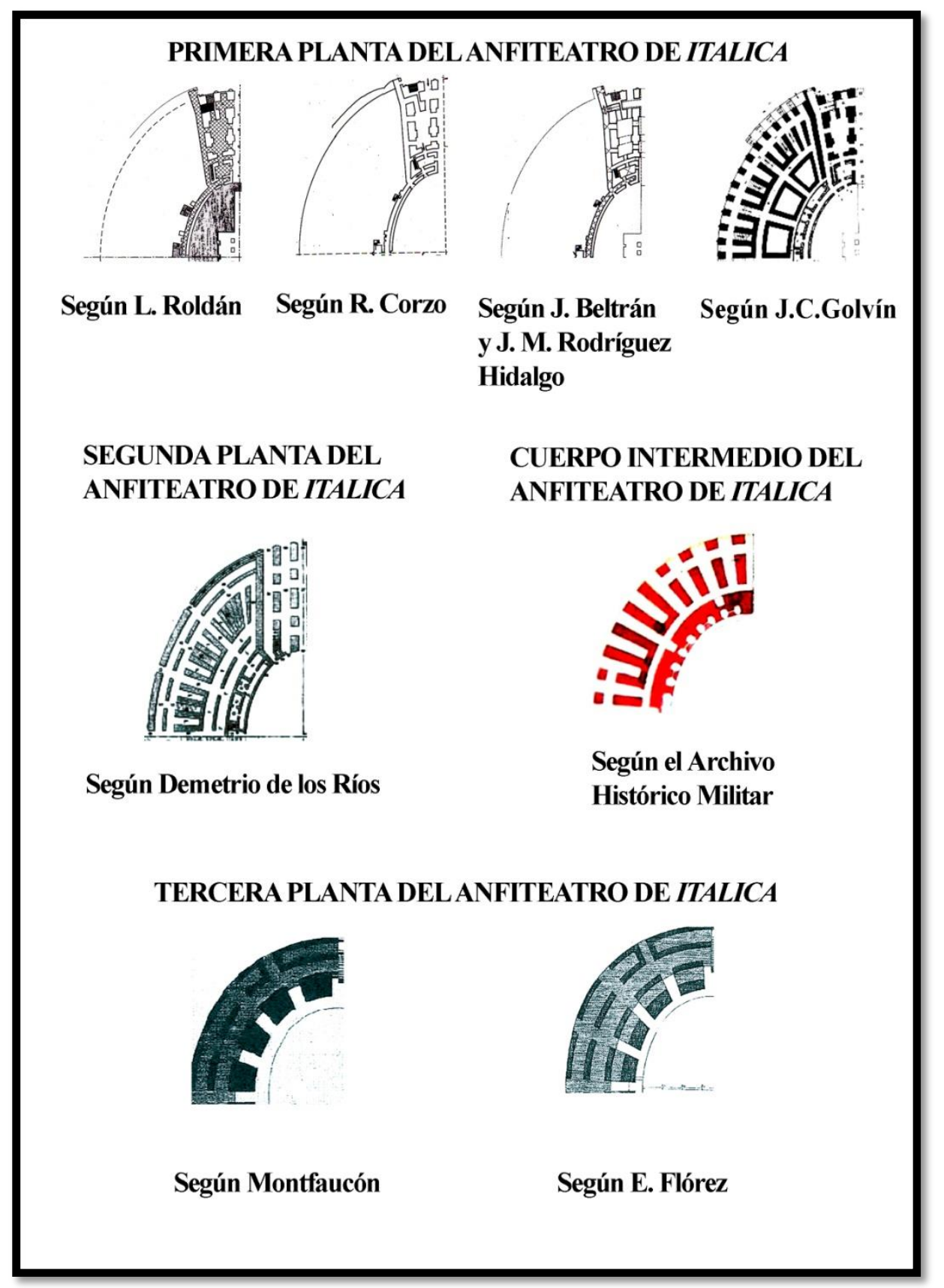

Fig. 3.- Cuadrantes de cada una de las plantas del anfiteatro según las investigaciones, sobre planos de M. Martí y B. de Montfaucón, E. Flórez, AHM, D. de los Ríos, L. Roldán, R. Corzo, J. Beltrán y J. M. Rodríguez, y J. C. Golvín.

\section{(c) (1) (2)}

La Revista Estudios es editada por la Universidad de Costa Rica y se distribuye bajo una Licencia Creative Commons Atribución-NoComercial-Compartirlgual 3.0 Costa Rica. Para más información envíe un mensaje a revistaestudios.eeg@ucr.ac.cr. 
Una nueva representación del anfiteatro la obtenemos gracias a F. Pérez Bayer quien a finales del siglo XVIII visitó Italica junto al dibujante Asencio Juliá, que presentamos como clave para determinar nuestras hipótesis por varios detalles que pasaremos a comentar, comparándolo con la planta proporcionada por el AHM (Salas, 2004, p. 682; León Gómez, 2006, p. 37) y mantendremos vigente respecto a los primeros grabados del siglo XIX (Fig. 2). En el dibujo de Asencio Juliá se contabiliza al menos hasta 14 filas de gradas, en el que tenemos que detallar que aunque sea una representación artística, el dibujante plasmaría los detalles que apreció de un edificio que mantenía en pie su tercer cuerpo, pues de lo contrario, si hubiese contemplado lo que se cree de los cuerpos actuales, lo habría tal y como lo hubiese contemplado.

El detalle lo marcamos en primer lugar en los lados este y oeste que presentan una destrucción por un momento lógica al tener en cuenta que el edificio se conformaría en parte sobre dos cerros y habría canalizado un pequeño arroyo, por lo que el problema de los terremotos y de las arcillas expansivas que sufre la zona, provocaría la dilatación y contracción del terreno al paso del tiempo y los consiguientes derrumbes. El segundo detalle más importante es el de la colmatación pues parece que se acerca a una praecintio que da acceso a los vomitoria, contemplándose cómo bajo ella continúa el graderío. En este momento debemos prestar atención al perfil realizado por el AHM donde contemplamos lo que se ha creído el podium y nosotros hemos interpretado como cuerpo intermedio sobre el que se erige la tercera cavea. Son las primeras gradas de este perfil lo que se representa en el dibujo de A. Juliá pues vemos cómo en el perfil se representa una galería interna con un acceso escalonado hacia el graderío, lo que demostraría que los vomitoria se encontrarían unas gradas por encima del cuerpo intermedio, el cual aparece en planta representado con muchas estancias, motivo a tener en cuenta en los siguientes grabados.

Los ingenieros militares del siglo XVIII pretendieron restituir el anfiteatro, proporcionándonos un perfil en el que contamos veintiocho filas de grada que 
consideramos excesivas y las hemos corregido según nuestra digitalización, que sigue el modelo del anfiteatro de Nimes en cuanto a estructura interna al contar éste con un cuerpo intermedio al que le sigue unas veinte filas de gradas, que curiosamente son las descritas por R. Caro para el caso italicense, y hemos recalculado digitalmente con la sorprendente coincidencia de las medidas que nos presenta los planos analizados, proporcionándonos el espacio suficiente para establecer un porticus in summae cavea relativamente amplio gracias a incluir el trazado de la escalera perimetral por el interior del edificio como nos indicaba Demetrio $(1862,30)$.

A principios del siglo XIX, Alexandre Laborde nos deja un nuevo detalle que refuerza nuestra hipótesis, pues dibuja un edificio muy destruido y colmatado en una visión desde el interior de una bóveda. Al fondo recrea el cuerpo intermedio y unos vomitoria con una serie de filas de gradas iguales a las que vemos en el perfil del AHM (Carriazo, 1935, p. 31; Beltrán Fortes y Rodríguez Hidalgo, 2004, p. 36; Salas, 2004, p. 223). De la misma forma lo vemos en el dibujo de Taylor de 1832, momento en el que el edificio estaba siendo reducido a escombros (León, 1993, p. 51). En esta ocasión vemos en primer plano unos jinetes sobre una arena muy colmatada, lo que no deja de mostrarnos el detalle del cuerpo intermedio gracias a uno de los vanos representados, al mismo tiempo que unas filas de gradas antes de acceder a los vomitoria. Poco tiempo después, en 1835, David Roberts (Canto, 1999, p. 187; Caballos, 2010, p. 73) nos deja un nuevo detalle en su representación del anfiteatro pues distinguimos el cuerpo intermedio marcado por una línea sobre la que varios hombres parecen dialogar al fondo en su dibujo. Sobre el mismo se erigen varias filas de gradas antes de llegar a los vomitoria. Esta imagen sería la que vería Demetrio de los Ríos en su primer contacto con el anfiteatro durante la década de los años cuarenta del siglo XIX. Demetrio dejó una acuarela del edificio con el detalle de las aperturas centrales del cuerpo intermedio, que se corresponden a las que detectamos en la planta del AHM. Si tenemos en cuenta las medidas actuales del edificio, respecto a la altura de las

\section{(c) (i) (2) (2)}

La Revista Estudios es editada por la Universidad de Costa Rica y se distribuye bajo una Licencia Creative Commons Atribución-NoComercial-CompartirIgual 3.0 Costa Rica. Para más información envíe un mensaje a 
Revista Estudios, (36), 2018.

Junio 2018-Noviembre 2018

ISSN 1659-3316

Mendoza Álvarez José David

gradas, esta colmatación representada corresponde a 18 metros hasta la parte superior del cuerpo intermedio, el cual está descrito con unas dimensiones de $2,9 \times 3 \mathrm{~m}$, que correspondería con los 15 metros donde termina en la actualidad la media cavea.

Aún a mediados del siglo XIX, el anfiteatro tenía en pie parte de su tercera cávea que fue desmontada por el cuerpo de ingenieros encargados de las reparaciones de la carretera de Extremadura, polémico hecho que desde pronto fue denunciado, tomando gran repercusión desde 1855 hasta 1860, denunciado con insistencia por Demetrio de los $\operatorname{Rios}^{5}$ (CASE/9/7970/015(19)). Además de la colmatación, Demetrio se enfrentó ya como director de las excavaciones desde ese año, a un edificio muy mermado por todo el daño sufrido para la extracción de su material, desapareciendo por completo lo que restaba del tercer nivel y desmoronándose el segundo tal y como había indicado Demetrio cuando el cuerpo de ingenieros comenzó a vaciar las bóvedas y estancias que encontraban ${ }^{6}$ (CASE/9/7970/015(35)). Por ese motivo, la interpretación que se le da a la planta de Demetrio es que correspondería al segundo cuerpo pues el detalle lo vemos en las dimensiones continuas del perímetro de la elipse y el ángulo de las galerías que establece como principales, siendo los niveles actuales diferentes, conformados por dos galerías radiales inclinadas con respecto al pasillo principal del eje mayor, además de poseer estancias a ambos lados del mismo, detalle que no se contempla en la planta de Demetrio.

Esta deducción nos hace determinar la configuración de la fachada mediante pilares con columnas adosadas en la forma que actualmente lo distinguimos, pero además se configuraría con una serie de columnas confeccionando un pórtico monumental propio de un edificio de este tipo. Para demostrar nuestra hipótesis debemos indicar que durante las excavaciones de la fachada a principios del siglo

\footnotetext{
5 Véase http://www.cervantesvirtual.com/portales/san_juan_de_la_cruz/obra/oficio-de-traslado-al-directorgeneral-de-agricultura-industria-y-comercio-en-el-que-se-describe-el-nuevo-destrozo-efectuado-en-distintoslugares-de-las-ruinas-de-italica-se-pide-a-la-real-academia-de-la-historia-eleve-su-queja-al-gobierno-y-seproponen-algunas-mediadas-para-su-conservacion/

${ }^{6}$ Véase http://www.cervantesvirtual.com/obra/litografia-de-la-planta-y-seccion-del-anfiteatro-de-italica/
}

La Revista Estudios es editada por la Universidad de Costa Rica y se distribuye bajo una Licencia Creative Commons Atribución-NoComercial-CompartirIgual 3.0 Costa Rica. Para más información envíe un mensaje a revistaestudios.eeg@ucr.ac.cr. 
XX se localizó un capitel corintio labrado en todas sus caras, lo que descartaría que fuese realizado con el fin de embutirse en los pilares a modo de semicolumna, y de la misma forma en las excavaciones de la fosa bestiaria se halló un tambor de columna estriado (Fig. 4). Un estudio arquitectónico avalaría tal hipótesis al demostrar como necesario la colocación de columnas en ese sector para evitar el hundimiento del resto del edificio. Este hecho sería argumentado además con las descripciones de Demetrio respecto a la fachada y a la escalera perimetral (De los Ríos, 1862, p. 24), con la sorpresa al digitalizar su planta y comprobar que corresponden al milímetro con las medidas actuales y disposición de los huecos por donde transcurrirían tales escaleras. De esta forma, vemos el paralelo más inmediato de fachada en el anfiteatro de Cagliari (Pala, 2002, p. 22; Dadea, 2006, p. 6-9). 


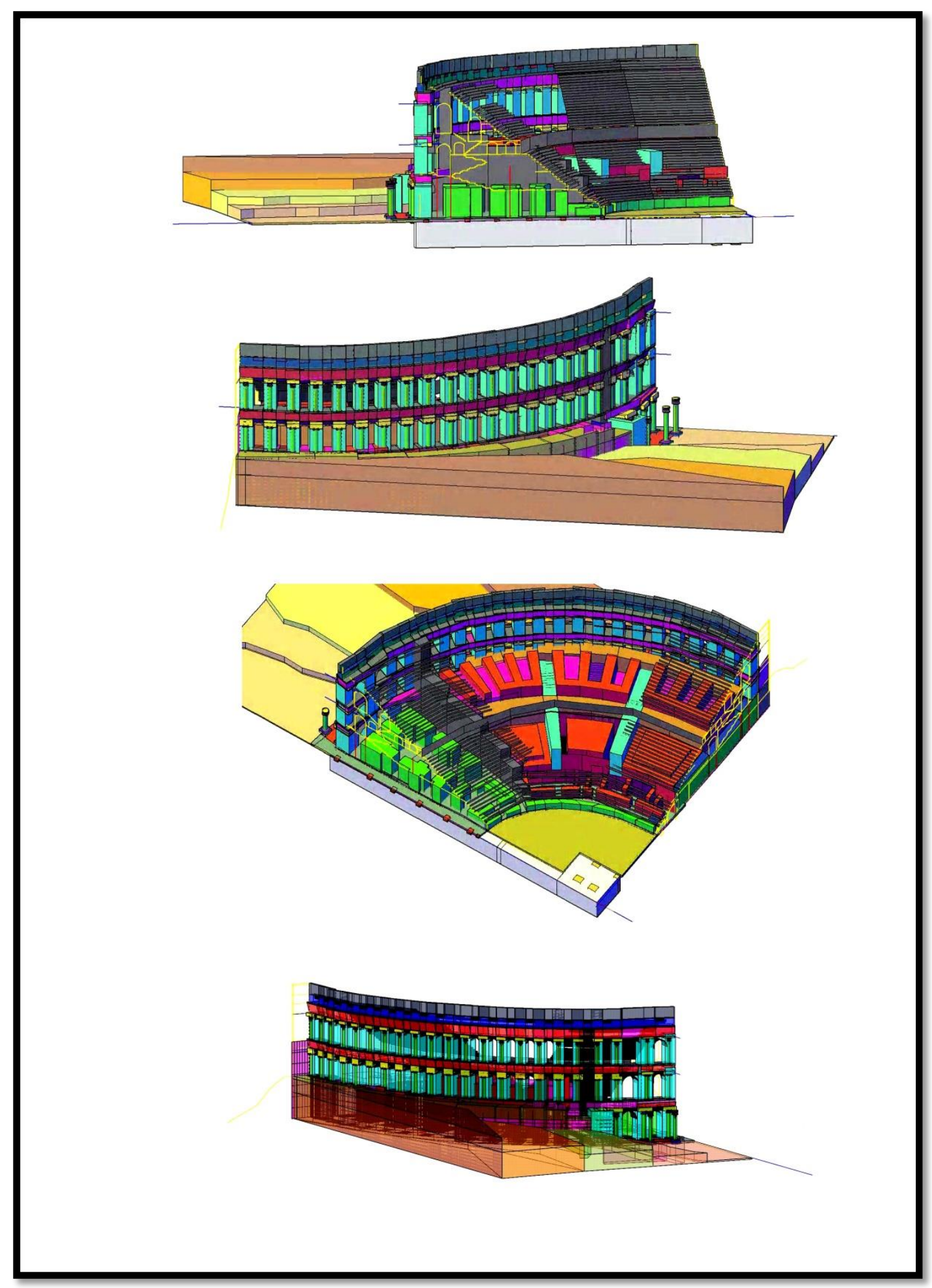

Fig. 4.- Digitalización de la planta y alzado del anfiteatro y restitución de las partes que faltan, apreciándose las propuestas para las fachadas principales porticadas, escalera (c) (i) (2) (2)

La Revista Estudios es editada por la Universidad de Costa Rica y se distribuye bajo una Licencia Creative Commons Atribución-NoComercial-Compartirlgual 3.0 Costa Rica. Para más información envíe un mensaje a revistaestudios.eeg@ucr.ac.cr. 
perimetral por el interior del conjunto, y cuerpo intermedio de separación entre la segunda y tercera cávea.

Y gracias a todo este análisis, hemos podido determinar su capacidad, en la que por lo general se establece que un anfiteatro triplicaba el aforo de la población en la que se establece, con el fin de acoger espectadores venidos de otros lugares (Ceballos, 2007a, p. 442), siendo para Italica estimada una población entre 8.00010.000 habitantes (Blázquez, 1982, p. 312; Pellicer, 1999, p. 188) mientras que se estima un aforo entre 20.000 y 25.000 espectadores (García y Bellido, 1960, p. 120; Blázquez, 1988, p. 181; Boatwright, 1997, p. 220; Ceballos y Ceballos, 2003, p. 59; Hidalgo, 2008, p. 223; Bellido, 2009, p. 35), hecho que hemos recalculado conforme a nuestras propuestas de restitución edilicia y tomando como media para cada persona pie y medio (0,45 m) (Canto, 1986, p. 52; Golvín, 1988, p. 387; Almagro y Almagro-Gorbea, 1994, p. 153), dándonos como resultado una cifra algo mayor, como veremos a continuación. Esta gran capacidad demostraba la importancia que tendría Italica a la hora de ofrecer juegos, disponiéndose para acoger grandes multitudes que sin duda vendrían de poblaciones cercanas.

Para establecer un aforo acorde con nuestra investigación, hemos realizado una serie de cálculos que determinan con gran precisión el número de espectadores que pudo llegar a tener el anfiteatro de Italica. En primer lugar hemos digitalizado las medidas completas de la planta del anfiteatro, con la restitución ideal según nuestras hipótesis. En segundo lugar, hemos establecido, siguiendo nuestras hipótesis, las elipses que conformarían cada sector del edificio, desde el podium hasta la terraza, determinando todas las elipses de cada una de sus filas de gradas. Una vez obtenidas todas las elipses, se tendría que calcular el perímetro de cada una de ella según la fórmula como ecuación más aproximada a la obtención de una elipse:

$$
\mathrm{P}=2 \pi \sqrt{\left(a^{2}+b^{2}\right) / 2}
$$

Donde $P$ es el Perímetro; $a$ es el radio menor; $b$ es el radio del eje mayor. 
Tras ello, calculamos cada uno de los radios menores y mayores y le aplicamos la fórmula. Una vez obtenido una cifra total, restamos los espacios de las escalinatas que separan todos los cunei, las de todos los vomitoria del segundo y tercer cuerpo, y la de los accesos del primer cuerpo, dependiendo de las filas de gradas a las que se le debían de aplicar, pues los vomitoria y accesos correspondían a un número limitado de filas mientras que las escalinatas se debían aplicar a todas las gradas del segundo y tercer cuerpo, hecho que nos reservamos un pequeño margen de error, respecto a algún otro vano que pudiese tener del cual no tengamos constancia, lo que nos hace establecer una cifra aproximada y no absoluta. Después de realizar este cálculo, dividimos el total por pie y medio que se establece para una plaza estándar, que rodeamos a 0,45 metros.

Una vez establecido todos estos cálculos, y teniéndose en cuenta los espacios que habría que restar, el aforo se eleva a 24.589 plazas. Pero nuestra investigación no se detiene en este punto, pues si analizamos lo establecido por Demetrio, obtiene un total de 21.300 espectadores, indicando que se podría aumentar a 25.000 teniéndose en cuenta el espacio que él no se aventuró en restituir (De los Ríos, 1862, p. 82). Esta cifra ha sido copiada por muchos autores, como hemos visto, e incluso ampliada sin criterio alguno. Nosotros hemos propuesto un cálculo lógico y lo hemos demostrado, por lo que podemos asegurar un número, aunque no exacto debido a lo comentado con anterioridad, si aproximado con un margen de error de \pm 100 espectadores. Ahora bien, si añadimos lo calculado por Demetrio para los espectadores que podían ocupar el podium, los excuneatos, y los que se establecerían en la terraza, cuyo número se eleva a 2.980 (De los Ríos, 1862, p. 82), la cifra nuestra aumentaría hasta los 27.569 espectadores. Pero ahí no queda la cosa, pues si Demetrio no tuvo en cuenta el cuerpo intermedio, el cual se compone de forma similar al podium, aunque con una amplitud mayor, debemos estimar al menos el mismo número que Demetrio propuso para el podium, que sumándolo a nuestro cálculo supondrían un total de 27.829 espectadores con \pm 100 de margen de error. Resumiendo este 
Revista Estudios, (36), 2018.

Junio 2018-Noviembre 2018

ISSN 1659-3316

Mendoza Álvarez José David

apunte, no podemos redondear cifras pues se alejaría de la realidad, por lo que fijaremos esta cifra como la estimada según nuestra investigación, adaptada a las hipótesis de restitución y nueva configuración del anfiteatro, en el que todas las medidas se presentan digitalizadas.

\section{4.- CONCLUSIONES}

Finalmente debemos presentar al anfiteatro de Italica como uno de los mayores del mundo, además de haber indicado una nueva restitución en la que destacamos fundamentalmente el nuevo elemento arquitectónico que ha condicionado toda la historiografía del edificio, y la imagen que de él se tenía, denominándolo cuerpo intermedio de separación entre la media y summae cavea, así como una fachada principal porticada para un perímetro continuo de la línea de la elipse, tanto al este como al oeste, en la que podemos ver tres cuerpos de arcadas mientras que al norte y sur, al conformarse sobre los cerros, presentaría dos cuerpos de arcadas. De esta forma, hemos calculado la altura respecto al nivel de la arena, elevándose el edificio hasta los 35,92 metros, frente a los 22,46 que proponía Demetrio (1862, pp. 115-116). Así mismo, esta nueva restitución nos ha permitido realizar los cálculos de su aforo que alcanzaría los 27.829 espectadores. Un último apunte lo señalamos en la determinación de las plantas que correspondería a cada nivel del anfiteatro (Fig. 3), pues gracias al análisis historiográficos hemos podido determinar como la primera planta más acercada a las medidas reales que presenta el edificio, la de Golvín (1988) y la realizada por J. Beltrán y J. M. Rodríguez Hidalgo (2004); la de Demetrio (1862) para el segundo cuerpo; la del AHM para el cuerpo intermedio; y la de Martí (1711) y Flórez (1776) para el tercer cuerpo.

Los anfiteatros fueron considerados como las construcciones más emblemáticas de los romanos, simbolizadas por su gran habilidad en ingeniería y arquitectura, con una gran connotación religiosa y militar (Wilson, 1993, p. 391). Por ello, el edificio italicense muestra parecidos en numerosos anfiteatros que señalamos

\section{(c) (i) (2)}

La Revista Estudios es editada por la Universidad de Costa Rica y se distribuye bajo una Licencia Creative Commons Atribución-NoComercial-CompartirIgual 3.0 Costa Rica. Para más información envíe un mensaje a 
como resultado de nuestra investigación en la que hemos tenido que considerar la edilicia adrianea para establecer los mejores ejemplos (Solana y Sagredo, 2006, p. 35; Benedetta, 2000, p. 13), donde será Nimes el que conformaría un gran paralelo respecto a la estructura interna del edificio (De los Ríos, 1862, p. 31; Carrasco y Jiménez, 2008, p. 34). No obstante, también encontramos el edificio de Cagliari (Dadea, 2006, p. 34) que presenta no solo una fachada como la que hemos dispuesto para el de Italica, sino que el mismo se ubica entre montañas, al tiempo que dispone también de un cuerpo intermedio y misma cronología. Debemos señalar, que el modelo fundamental para ello siempre ha sido el Coliseo (Beltrán Llorís, 1997, p. 29; Plácido, 2002-2003, p. 13; Hidalgo, 2008, p. 223). No obstante, otros edificios que se muestran muy similares al italicense son los de Carthago Noua (Pérez Ballester, San Martín y Berrocal, 1994, pp. 110-111; Muñoz Garrido, 2002, p. 323); Tarraco (Dupré, 1994, p. 80); Emporiom (Golvín, 1988, p. 121; Sanmartí, Aquilue y Castanyer, 1994, p. 122); Segobriga (Golvín, 1988, p. 109; Almagro y Almagro-Gorbea, 1994, p. 144); Emerita Augusta, determinado como estructura hueca por Golvín (1988, pp. 109-111) aunque adaptado a la topografía (Bendala y Durán Cabello, 1994, p. 249); Trier con su peculiar construcción en medio de la muralla en su eje menor este oeste, mientras que al norte presentaría tres niveles de arcadas en su puerta principal (Breitner, 2011, pp. 40-41); o el de Villavieja, en Almería, un pequeño anfiteatro con partes del mismo excavadas en las rocas (Cara y Rodríguez López, 1987, pp. 48-49).

Por tanto, esta estructura intermedia entre las cáveas se localiza en anfiteatros principalmente con la misma cronología adrianea, si bien es cierto que el modelo para ello se determina en el anfiteatro Flavio. Debemos entenderlo como una barrera física de separación entre las gradas para evitar disturbios al mismo tiempo que presentaría un diseño funcional al soportar el peso, empujes y tensiones del resto del edificio en sus niveles superiores. Así mismo, este nuevo elemento debe ser diferenciado del resto de cualquier cávea, y por ello acuñamos

\section{(a) $(\mathbb{Q} \Theta$}

La Revista Estudios es editada por la Universidad de Costa Rica y se distribuye bajo una Licencia Creative Commons Atribución-NoComercial-CompartirIgual 3.0 Costa Rica. Para más información envíe un mensaje a 
el nombre de cuerpo intermedio, como una estructura más dentro de la complejidad del diseño de los anfiteatros.

\section{5.- BIBLIOGRAFÍA}

Abascal, J. M. y Espinosa, U. (1989). La ciudad hispano-romana. Logroño.

Almagro, A. y Almagro-Gorbea, M. (1994). El anfiteatro de Segobriga. En J.M. Álvarez Martínez y J. J. Enriquez Navascues (Coords.). Bimilenario del anfiteatro Romano de Mérida. Coloquio Internacional el anfiteatro en la Hispania Romana (Mérida, 26-28 de noviembre de 1992), (pp. 139-176), Junta de Extremadura, Mérida.

Amela Valverde, L. (2011). Q. Pompeius Niger de Italica. Cuadernos de filología clásica: Estudios latinos, 31.1, 27-35.

Blázquez Martínez, J. M. (2006). Introducción a los escenarios en la antigua Grecia. En J. M. Blázquez Martínez (Ed.). Escenarios de España. Fomento de construcciones y contratos (pp. 14-27), Madrid.

- (1994). Posibles precedentes prerromanos de los combates de gladiadores romanos en la Península Ibérica. En J.M. Álvarez Martínez y J. J. Enriquez Navascues (Coords.). Bimilenario del anfiteatro Romano de Mérida. Coloquio Internacional el anfiteatro en la Hispania Romana (Mérida, 26-28 de noviembre de 1992) (pp. 31-44), Junta de Extremadura, Mérida.

- (1991). Religiones en la España antigua. Madrid.

- (1988). El urbanismo en Occidente. En Homenaje a Samuel de los Santos (pp. 179-183), Albacete.

- (1982). La Italica de Trajano y Adriano. En Italica (Santiponce, Sevilla): Actas de las primeras jornadas sobre excavaciones arqueológicas en Italica, Exma. Diputación Provincial de Sevilla, 1980 (pp. 293-298), Madrid.

Bellido Márquez, T. (2009). Panorama historiográfico del anfiteatro de Italica. Romula, 8, 33-64.

Beltrán Llorís, F. (1997). Lo mejor del Arte Romano I. Historia 16, 6, 25-29.

La Revista Estudios es editada por la Universidad de Costa Rica y se distribuye bajo una Licencia Creative Commons Atribución-NoComercial-Compartirlgual 3.0 Costa Rica. Para más información envíe un mensaje a revistaestudios.eeg@ucr.ac.cr. 
Beltrán Fortes, J. y Rodríguez Hidalgo, J. M. (2004). Italica: espacios de culto en el anfiteatro. Sevilla.

Bendala Galán, M. y Durán Cabello, R. (1994). El anfiteatro de Augusta Emerita: rasgos arquitectónicos y problemática urbanística y cronología. En J.M. Álvarez Martínez y J. J. Enriquez Navascues (Coords.). Bimilenario del anfiteatro Romano de Mérida. Coloquio Internacional el anfiteatro en la Hispania Romana (Mérida, 2628 de noviembre de 1992) (pp. 247-264), Junta de Extremadura, Mérida.

Benedetta, A. (2000). Villa Adriana. Guida. Roma.

Boatwright, M. T. (1997): Italica y la magnificencia urbana de Adriano. En A. Caballos Rufino y P. León Alonso (Eds.). Italica MMCC. Actas de las jornadas del 2200 Aniversario de la Fundación de Italica (Sevilla, 8-11 noviembre 1994) (pp. 220-233), Sevilla.

Braun, G. y Hogenberg, F. (1572-1618). Civitates orbis terrarum. Colonia.

Breitner, G. (2011). Architekturmodelle in der Ausstellung des Rheinischen Landesmuseums Trier. Funde und Ausgrabungen im Bezirk Trier, 43, 37-47.

Caballos Rufino, A. (Ed.) (2010). Ciudades romanas de Hispania 7: ItalicaSantiponce. Municipium y Colonia Aelia Augusta Italicensium. Roma.

Cabrero Piquero, J. y Cordente Vaquero, F. (2011). Los oficios de la diversión en Roma. Espacio, tiempo y forma. Serie II: Historia Antigua, 24, 363-379.

Canto, A. M. (1999). La Vetus Urbs de Italica, quince años después: La planta hipodámica de D. Demetrio de los Ríos, y otras novedades. CuPAUAM, 25, 145192.

- (1986). Némesis y la localización del circo de Italica. BSAA, 52, 47-81.

Cara Barrionuevo, L. y Rodríguez López, J.M. (1987). El anfiteatro romano de Villavieja (Berja, Almería). En XVIII CNA (Las Palmas de Gran Canarias, Santa Cruz de Tenerife, 1985) (pp. 41-62), Tenerife.

Caro, R. (1634). Antigüedades y principado de la ilustrísima ciudad de Sevilla y Chorographía de su convento jurídico, o antigua cancillería, dirigida al

\section{(a) $(\triangle \odot$}

La Revista Estudios es editada por la Universidad de Costa Rica y se distribuye bajo una Licencia Creative Commons Atribución-NoComercial-CompartirIgual 3.0 Costa Rica. Para más información envíe un mensaje a revistaestudios.eeg@ucr.ac.cr. 
Revista Estudios, (36), 2018.

Junio 2018-Noviembre 2018

ISSN 1659-3316

Mendoza Álvarez José David

excelentísimo señor Don Gaspar de Guzmán, Conde Duque de Sanlúcar la Mayor.

Sevilla.

Carrasco Gómez, I. y Jiménez Hernández, A. (2008). A cerca de los edificios de espectáculos en Colonia Augusta Firma Astigi (Écija, Sevilla). Romula, 7, 7-52.

Carriazo, J. de M. (1935). Les fovilles d'Italica. Aperçu historique. Bulletin de I'Office International des Instituts d'Archéologie et d'Histoire de l'Art, 1.3, 23-33.

Ceballos Hornero, A. y Ceballos Hornero, D. (2003). Los espectáculos del anfiteatro en Hispania. Iberia, 6, 57-70.

Ceballos Hornero, A. (2007a). Geografía y cronología de los ludi en la Hispania romana. Caesaraugusta, 78, 437-454.

- (2007b). El coste de los espectáculos gladiatorios en las ciudades del occidente romano. Archivo Español de Arqueología, 80, 107-118.

Chisvert Jiménez, N. (1987). Topónimos de Italica: urbanismo y arquitectura. Sevilla.

Cortijo Cerezo, M. L. (2008): El Itinerario de Antonino y la provincia Baetica, Habis, 39, 285-308.

Corzo Sánchez, R. (2002). La fundación de Italica y su desarrollo urbanístico. En J. L. Jiménez Salvador y A. Ribera i Lacomba (Eds.). Valencia y las Primeras Ciudades de Hispania (pp. 123-135), Valencia.

- (1994). El anfiteatro de Italica. En J.M. Álvarez Martínez y J. J. Enriquez Navascues (Coords.). Bimilenario del anfiteatro Romano de Mérida. Coloquio Internacional el anfiteatro en la Hispania Romana (Mérida, 26-28 de noviembre de 1992) (pp. 187-212), Junta de Extremadura, Mérida.

Dadea, M. (2006). L'anfiteatro romano di Cagliari. Sassari.

De los Ríos, D. (1862). Memoria arqueológico-descriptiva del anfiteatro de Italica. Madrid.

De los Ríos, R. A. (1916a). El anfiteatro de Italica. Revista de Archivos, Bibliotecas y Museos, $3^{a}$ época, 20.34, 381-410.

\section{(C) $(00$}

La Revista Estudios es editada por la Universidad de Costa Rica y se distribuye bajo una Licencia Creative Commons Atribución-NoComercial-CompartirIgual 3.0 Costa Rica. Para más información envíe un mensaje a revistaestudios.eeg@ucr.ac.cr. 
- (1916b). Excavaciones en el anfiteatro de Italica. Memoria de los trabajos practicados en 1915. Madrid.

Carriazo, J. (1935). Estado actual de las excavaciones de Italica: La manzana del gimnasio. En Anuario del Cuerpo Facultativo de Archiveros, Bibliotecarios y Arqueólogos (pp. 305-321), Madrid.

De Medina, P. (1566). Libro de grandezas y cosas memorables de España. Alcalá de Henares.

De Morales, A. (1575). Las antigüedades de las ciudades de España. Alcalá de Henares.

Dupré, X. (1994). El anfiteatro de Tarraco. En J.M. Álvarez Martínez y J. J. Enriquez Navascues (Coords.). Bimilenario del anfiteatro Romano de Mérida. Coloquio Internacional el anfiteatro en la Hispania Romana (Mérida, 26-28 de noviembre de 1992) (pp. 79-90), Junta de Extremadura, Mérida.

Esperandieu, E. (1933). L'amphitheatre de Nimes. París.

Fabié, A. M. (1892). El nuevo bronce de Italica. Boletín de la Real Academia de la Historia, 21, 385-397.

Flórez, E. (1776). España Sagrada. Teatro Geográfico Histórico de la Iglesia de España. Tomo XII: De las Iglesias sufragáneas antiguas de Sevilla: Egabro, Elepla, Eliberi, Italica, Málaga y Tucci. Madrid.

García Naranjo, J. (1951). El anfiteatro romano de Italica. Conferencia de divulgación arqueológica. Sevilla.

García y Bellido, A. (1960). Andalucía Monumental. Italica. Granada.

Garrido Moreno, J. (2005). El anfiteatro: una oscura imagen de la antigua Roma. Berceo, 149, 153-178.

Golvín, J. C. (1988). L'Amphitheatre Romain. París.

Gómez Pantoja, J. L. (2006). Entre Italia e Hispania: los gladiadores. En A. Sartori y A. Valvo (Eds.). Hiberia-Italia, Italia-Hiberia (pp. 167-180), Milán.

González Blanco, A. (Coord.) (1988). Vías romanas del sureste, pp. 243-245, Murcia.

\section{(c) (i)(2) (2)}

La Revista Estudios es editada por la Universidad de Costa Rica y se distribuye bajo una Licencia Creative Commons Atribución-NoComercial-Compartirlgual 3.0 Costa Rica. Para más información envíe un mensaje a revistaestudios.eeg@ucr.ac.cr. 
González Parrilla, J.M. (2002). Archer Milton Huntington y la arqueología italicense de fines del siglo XIX. Habis, 33, 487-499.

Gros, P. (1994): L'amphitheâtre dans la ville. Politique "culturelle" et urbanisme aux deux premiers siècles de l`Empire. En J.M. Álvarez Martínez y J. J. Enriquez Navascues (Coords.). Bimilenario del anfiteatro Romano de Mérida. Coloquio Internacional el anfiteatro en la Hispania Romana (Mérida, 26-28 de noviembre de 1992) (pp. 13-30), Junta de Extremadura, Mérida.

Guerra García, P. (2005). La red viaria romana: investigando las arterias invisibles, Actas del cuarto Congreso Nacional de Historia de la Construcción, Cádiz, 27-29 de enero de 2005, COAAT (pp. 561-569), Cádiz.

Hidalgo Prieto, R. (2012). Sobre el supuesto centro de culto cristiano del anfiteatro de Córdoba. Habis, 43, 249-274.

- (2008). Anfiteatros. En P. León Alonso (Coord.). Arte romano de la Bética. Arquitectura y Urbanismo (pp. 223-232), Sevilla.

Larrey Hoyuelos, E., Ramón Girón, F. J. y Verdugo Santos, J. (1998). Intervención arqueológica en el anfiteatro de Italica. Campaña de 1998. AAA 1998, 1, 10811096.

León Alonso, P. (1993). La ruinas de Italica: una estampa arqueológica de prestigio. En J. Beltrán Fortes y F. Gascó (Eds.). La Antigüedad como argumento. Historiografía de Arqueología e Historia Antigua en Andalucía (pp. 29-62), Sevilla.

León Gómez, A. (2006). Imágenes arqueológicas de la España ilustrada. El teatro romano de Sagunto en el siglo XVIII. Sevilla.

Lipsio, J. (1598). De Amphitheatro liber. Amberes.

Luzón Nogué, J. M. (1999). Sevilla la Vieja. Un paseo histórico por las ruinas de Italica. Sevilla.

Maiuri, A. (1955). Studi e ricerche sull'Anfiteatro Flavio Puteolano. Academia di archeologia lettere e belle arti di Napoli. Memorie III. Nápoles.

Melchor Gil, E. (1992). Sistemas de financiación y medios de construcción de la red viaria hispana, Habis, 23, 121-137.

\section{(c) (i) (2)}

La Revista Estudios es editada por la Universidad de Costa Rica y se distribuye bajo una Licencia Creative Commons Atribución-NoComercial-CompartirIgual 3.0 Costa Rica. Para más información envíe un mensaje a 
Mendoza Álvarez, J. D. (2017). Análisis historiográfico del anfiteatro de Itálica. Tesis Doctoral. Morrisville, Carolina del Norte (EEUU).

Morales Cara, M. (2005). La esclavitud en las colonias romanas de Andalucía. Granada.

Muñoz Garrido, J. (2002). El proyecto romano construido en Lusitania. Madrid.

Pala Nuolo, P. (2002). L’anfiteatro romano di Cagliari. Nuoro.

Pellicer Catalán, M. (1999). Panorama de la arqueología de Italica. Boletín de la Real Academia de Bellas Artes de Santa Isabel de Hungría, 27, 175-202.

Pérez Ballester, J., San Martín Moro, P. A. y Berrocal Caparrós, C. (1994). El anfiteatro romano de Cartagena (1967-1992). En J.M. Álvarez Martínez y J. J. Enriquez Navascues (Coords.). Bimilenario del anfiteatro Romano de Mérida. Coloquio Internacional el anfiteatro en la Hispania Romana (Mérida, 26-28 de noviembre de 1992) (pp. 91-118), Junta de Extremadura, Mérida.

Pina Polo, F. (2007). Los espectáculos agonísticos en el occidente del Imperio romano. Salduie, 7, 143-156.

Plácido Suárez, D. (2002-2003). Leyes municipales y símbolos del poder: los fundamentos sociales de la dinastía flavia. Memorias de Historia Antigua, 23-24, 920.

Rodríguez Hidalgo, J. M. y Keay, S. (1995). Recent work at Italica. Procedings of the British Academy, 86, 395-420.

Rodríguez Hidalgo, J. M. (2012b). Hitos de una historia gráfica del descubrimiento de Italica. Italica, revista de arqueología clásica de Andalucía, 2, 13-27.

- (2012a). Italica. La Pompeya Española. En M. Almagro y J. Maier Allende (Eds.). De Pompeya al Nuevo Mundo. La corona española y la arqueología del siglo XVIII. Real Academia de la Historia. Patrimonio Nacional (pp. 123-143), Madrid.

- (2010). Historia de la investigación. En A. Caballos Rufino (Ed.). Ciudades romanas de Hispania 7: Italica-Santiponce. Municipium y Colonia Aelia Augusta Italicensium (pp. 17-34), Roma.

\section{(c) (†) (-)}

La Revista Estudios es editada por la Universidad de Costa Rica y se distribuye bajo una Licencia Creative Commons Atribución-NoComercial-CompartirIgual 3.0 Costa Rica. Para más información envíe un mensaje a 
Roldan Gómez, L. (1994). El anfiteatro de Italica. Técnicas y materiales de construcción. En J.M. Álvarez Martínez y J. J. Enriquez Navascues (Coords.). Bimilenario del anfiteatro Romano de Mérida. Coloquio Internacional el anfiteatro en la Hispania Romana (Mérida, 26-28 de noviembre de 1992) (pp. 213-238), Junta de Extremadura, Mérida.

- (1993). Técnicas constructivas romanas en Italica (Santiponce, Sevilla). Madrid. Salas Álvarez, J. (2009). La antigüedad clásica en la España Sagrada del Padre Henrique Flórez de Setién y Huidobro. Gerion, 27, 57-78.

- (2007). El viaje arqueológico a Andalucía y Portugal de Francisco Pérez Bayer. SPAL, 16, 9-24.

- (2004). La recuperación del patrimonio arqueológico de Andalucía durante la Ilustración (1736-1808). Sevilla.

Sanmartí-Grego, E., Aquilué, X., Castanyer, P., Santos, M. y Tremoleda, J. (1994). El anfiteatro de Emporiae. En J.M. Álvarez Martínez y J. J. Enriquez Navascues (Coords.). Bimilenario del anfiteatro Romano de Mérida. Coloquio Internacional el anfiteatro en la Hispania Romana (Mérida, 26-28 de noviembre de 1992) (pp. 119138), Junta de Extremadura, Mérida.

Sillières, P. (1990). Les voies de communication de l'Hispanie meridional. París.

Santos Yanguas, N. (2008). La nueva gladiatura cristiana en el marco de la gladiatura romana. Hispania Antiqua, 32, 183-212.

Solana Sainz, J. M. y Sagredos San Eustaquio, L. (2006). La política edilicia viaria en Hispania durante el reinado de Adriano. HAnt, 30, 35-86.

VVAA (1845). Enciclopedia española del siglo diez y nueve, o Biblioteca completa de Ciencias, Literatura, Artes y Oficios, Madrid, 167-173.

Wilson Jones, M. (1993). Designin Amphitheatres. Römische Mitteilungen, 100, 391-441.

\section{(c) (i) (9) (2)}

La Revista Estudios es editada por la Universidad de Costa Rica y se distribuye bajo una Licencia Creative Commons Atribución-NoComercial-CompartirIgual 3.0 Costa Rica. Para más información envíe un mensaje a 